\title{
Cerebral revascularization in cerebral proliferative angiopathy: a systematic review
}

\author{
Mohamed Somji, MD, ${ }^{1}$ James McEachern, MD, FRCPC, ${ }^{2}$ and Joseph Silvaggio, MD, FRCSC ${ }^{1}$ \\ ${ }^{1}$ Section of Neurosurgery and ${ }^{2}$ Department of Radiology, University of Manitoba, Winnipeg, Manitoba, Canada
}

OBJECTIVE Cerebral proliferative angiopathy (CPA) is considered a discrete vascular malformation of the brain separate from classical brain arteriovenous malformations (AVMs). It has unique angiographic characteristics and has been hypothesized to result from chronic cortical ischemia and perinidal oligemia. Treatment with cerebral revascularization has been proposed in an attempt to disrupt regional hypoperfusion and interrupt the angiogenesis that defines CPA. A systematic review of the literature pertaining to the role of cerebral revascularization may highlight a treatment paradigm for this rare disease.

METHODS A systematic review was performed in accordance with Preferred Reporting Items for Systematic Reviews and Meta-Analysis (PRISMA) guidelines. MEDLINE and Embase were searched from inception for papers relating to CPA. Included articles were categorized according to methodology (case series or imaging study) and treatment modality (conservative, radiation, endovascular, or revascularization). A synthesis was compiled summarizing the current evidence regarding cerebral revascularization in CPA.

RESULTS The initial search revealed 43 articles, of which 28 studies met the inclusion criteria. Nine studies were identified that described imaging findings, which suggested hemodynamic dysregulation and perinidal impairments in the cerebrovascular reserve could be identified compared to unaffected hemispheres and classical brain AVMs. Six studies including 7 patients undergoing indirect forms of cerebral revascularization were identified. Clinical and radiological outcomes following revascularization were favorable in all but one study.

CONCLUSIONS A small body of radiological and clinical studies has emerged, suggesting that CPA is a response to perinidal oligemia. While the long-term clinical efficacy of revascularization remains unclear, early results suggest that this may be a novel treatment paradigm for patients with CPA.

https://thejns.org/doi/abs/10.3171/2018.11.FOCUS18529

KEYWORDS cerebral proliferative angiopathy; cerebral revascularization; systematic review

$\mathrm{C}$ EREBRAL proliferative angiopathy (CPA) is considered a unique form of vascular malformation discrete from arteriovenous malformations (AVMs) of the brain. It is extremely rare, accounting for only $3.4 \%$ of brain $\mathrm{AVMs}{ }^{18}$ with typical characteristics on catheter angiography (Fig. 1). These include the absence of dominant arterial feeders, proximal artery stenosis, transdural arterial supply, "puddling" of contrast in the late arterial and early venous phase, a poorly circumscribed nidus, perinidal angiogenesis, and a large area of arteriovenous shunting but no early venous phase.$^{18} \mathrm{CPA}$ is difficult to treat owing to the large, often multilobar distribution of the malformation and interspersed normal brain tissue. In 2008, Lasjaunias et al. proposed the hypothesis that the hallmark characteristic of CPA-namely, diffuse proliferative angiogenesis-was a response to perinidal oligemia and chronic cortical ische- mia. ${ }^{18}$ They also suggested a treatment paradigm wherein revascularization was undertaken for demonstrable ischemia and targeted embolization for identifiable sources of hemorrhage. Since it was initially described, a number of case series and imaging studies evaluating the significance of regional ischemia have emerged. A systematic review of the literature pertaining to CPA and the role of cerebral revascularization may highlight a treatment paradigm for this difficult-to-treat condition.

\section{Methods}

\section{Search Strategy}

The systematic review was performed in accordance with Preferred Reporting Items for Systematic Reviews and Meta-Analysis (PRISMA) guidelines. ${ }^{23}$ Primary Eng-

ABBREVIATIONS AVM = arteriovenous malformation; $C B V=$ cerebral blood volume; $C P A=$ cerebral proliferative angiopathy; EDAS = encephaloduroarteriosynangiosis; PRISMA = Preferred Reporting Items for Systematic Reviews and Meta-Analysis; STA = superficial temporal artery; TTP = time to peak.

SUBMITTED October 1, 2018. ACCEPTED November 13, 2018.

INCLUDE WHEN CITING DOI: 10.3171/2018.11.FOCUS18529. 

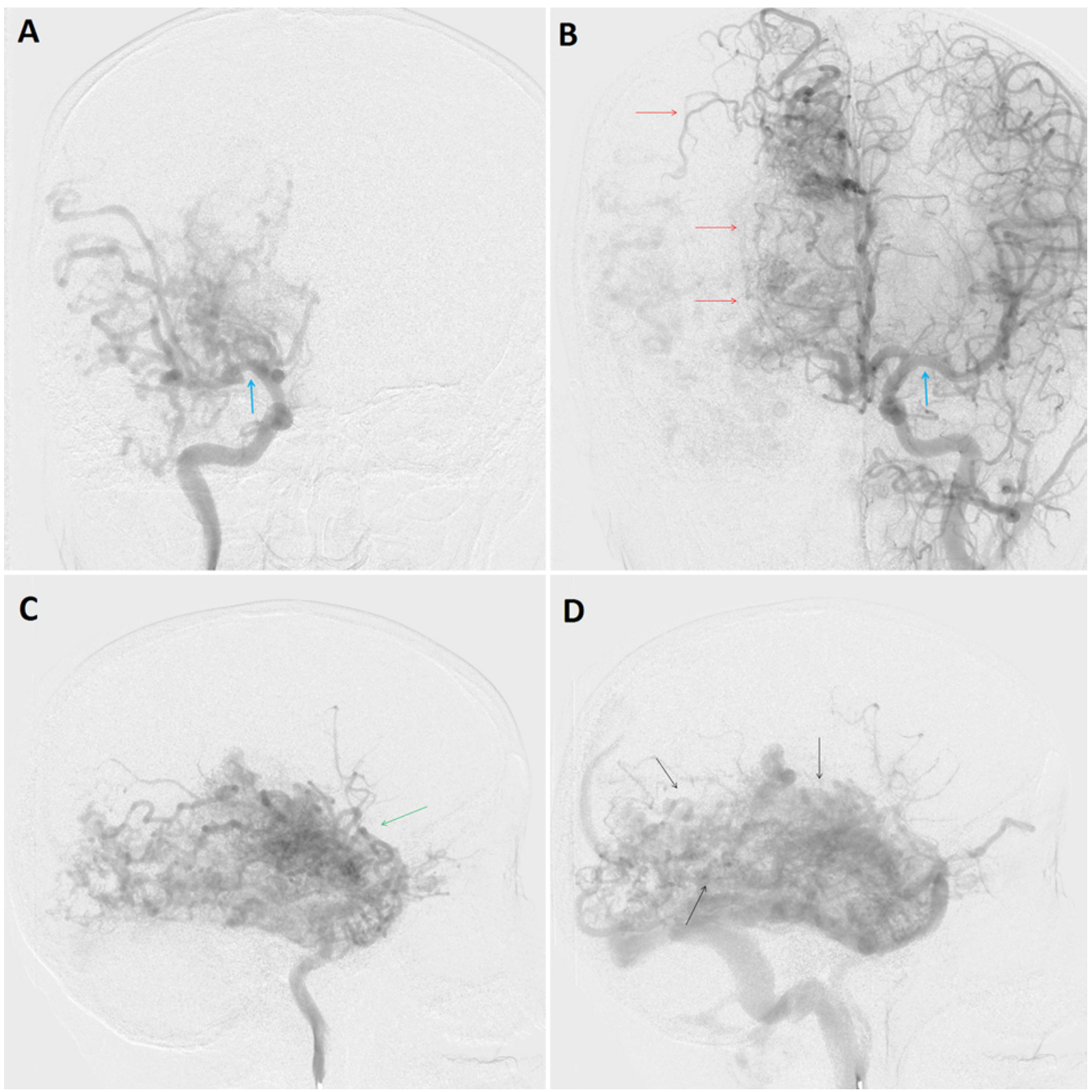

FIG. 1. Representative angiograms demonstrating CPA that occupies the right temporal and occipital lobes. A: Right internal carotid artery (ICA) angiogram obtained during the arterial phase with anteroposterior projection demonstrating no early venous phase, normal caliber of proximal vessels compared to unaffected side (blue arrow), and absence of dominant feeders. B: Left ICA angiogram during the late arterial phase with anteroposterior projection demonstrating proliferative vascularization involving right anterior cerebral artery territory (red arrows). C: Right ICA angiogram during the late arterial phase with lateral projection demonstrating a poorly defined nidus, large area of arteriovenous transit but without an early venous phase, and intranidal capillary angioectasias (green arrow). D: Right ICA angiogram during the venous phase with lateral projection demonstrating contrast stasis in the malformation, resulting in a "puddling" appearance (black arrows).

lish-language studies that described CPA were sought. MEDLINE and Embase were searched using the OVID interface from inception to July 2018 , including in-process and nonindexed citations. Search terms utilized were as follows: "cerebral" and "proliferative" and "angiopathy."

\section{Study Selection}

The primary author (M.S.) was responsible for study selection. After title and abstract review, all studies that satisfied the following inclusion criterion were selected for full-text review: studies pertaining to CPA.

After full-text review, studies fulfilling the following criteria were excluded: reviews of existing literature, conference abstracts, studies in which the diagnosis of CPA was claimed without catheter angiography, and studies not reporting pertinent clinical, imaging, or treatment findings. 


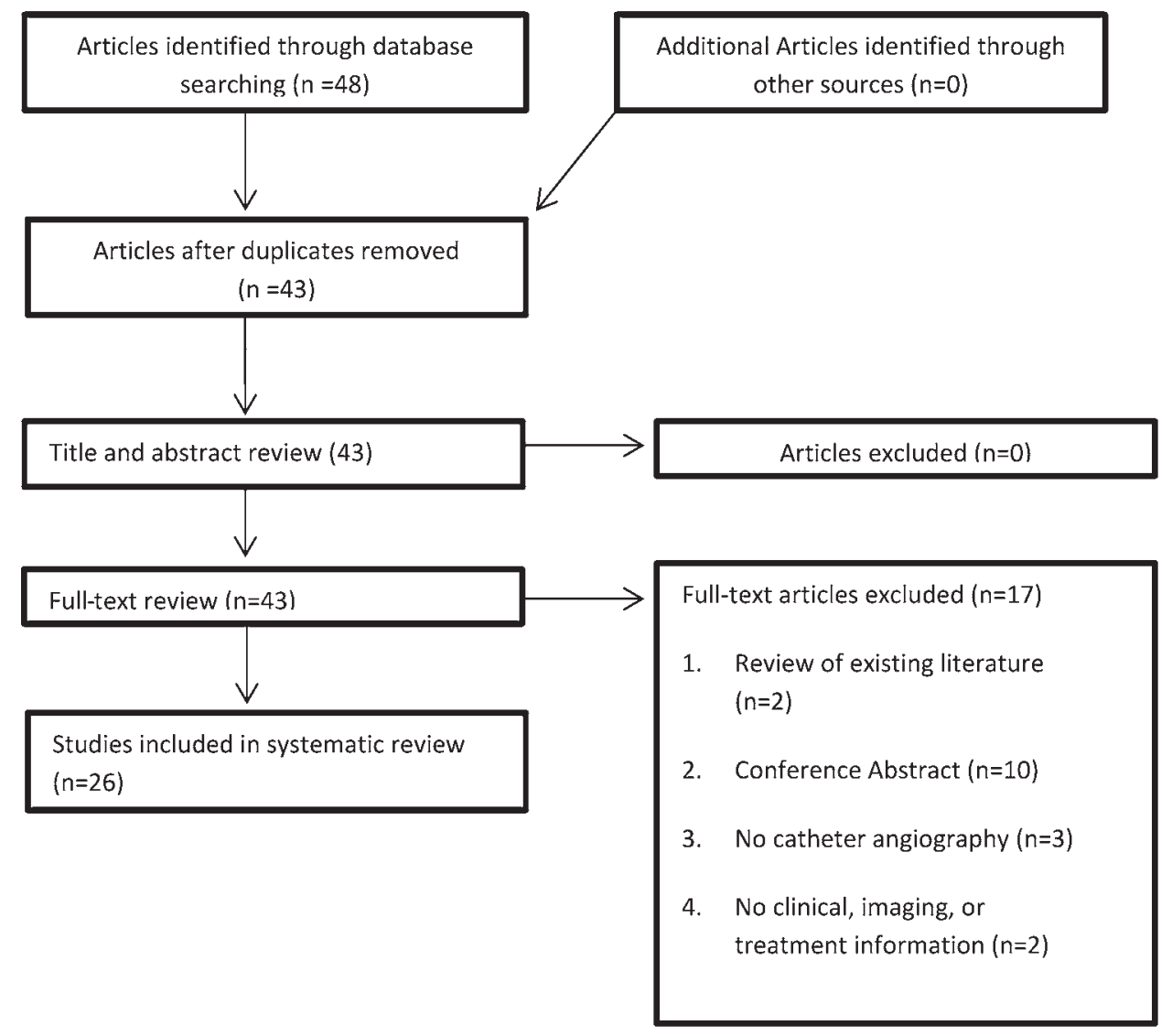

FIG. 2. Results of study selection with PRISMA flow diagram.

The remaining studies were included in the systematic review. References of the included studies were searched for additional relevant studies.

\section{Data Items}

Data items collected included the following: study type, treatment modality, sex, CPA location, clinical outcome, radiological outcome, follow-up duration, imaging modality, and key findings. Included studies were divided into two categories-clinical case series and/or imaging studies. Clinical series were further divided according to treatment modality-conservative, radiation therapy, endovascular embolization, or revascularization.

\section{Synthesis of Results}

A synthesis was compiled that summarized the findings of included studies with respect to the role of cerebral revascularization.

\section{Results}

\section{Study Selection}

The results of study selection are demonstrated in Fig. 2. In brief, 43 articles were found after database searching and removal of duplicates. After full-text review, 17 articles were excluded, leaving 26 included studies.

\section{Study Characteristics and Key Findings}

Of the 26 studies that met selection criteria, 9 studies described advanced imaging findings, 17 studies described a clinical case series, and 5 studies described both.

Table 1 summarizes the results of the imaging studies. Tables 2-5 demonstrate the results of the clinical series organized by treatment modality.

\section{Synthesis of Results Advanced Imaging Modalities}

Among imaging studies without a comparison group, all reported dysregulation of cerebral hemodynamics using various methodologies. Among studies utilizing MR perfusion, areas of cortex remote from the malformation were found to exhibit increased time to peak (TTP) and decreased cerebral blood volume (CBV). ${ }^{3,13,18,29}$ Converse$\mathrm{ly}$, regions within the malformation were found to demonstrate an increased CBV, taken to represent increased volume secondary to shunting..$^{18}$ There was agreement among these studies that increased transit times and TTP could be taken as evidence of relative hypoperfusion over the affected hemisphere..$^{13,18,29}$ Decreased peri-lesional uptake was demonstrated among three studies utilizing SPECT as an imaging modality. ${ }^{13,15,19}$ Acetazolamide-stressed SPECT demonstrated further impairment of cerebrovas- 
TABLE 1. Advanced imaging studies

\begin{tabular}{|c|c|c|c|c|}
\hline Authors \& Year & $\begin{array}{l}\text { No. of CPA } \\
\text { Pts Imaged }\end{array}$ & $\begin{array}{l}\text { Imaging } \\
\text { Modality }\end{array}$ & $\begin{array}{l}\text { Comparison } \\
\text { Group }\end{array}$ & Key Findings \\
\hline Ducreux et al., 2002 & 1 & MR perfusion & None & $\begin{array}{l}\text { Local \& remote dysregulation of cerebral perfusion, including regions of } \\
\text { relatively increased \& decreased perfusion parameters }\end{array}$ \\
\hline Lasjaunias et al., 2008 & 7 & MR perfusion & None & $\begin{array}{l}\text { W/in the vascular malformation, increased CBV \& slightly decreased TTP } \\
\text { identified. Areas of cortex remote from the malformation, increased TTP, \& } \\
\text { decreased CBV taken to be indicative of widespread hypoperfusion }\end{array}$ \\
\hline Fierstra et al., 2011 & 4 & BOLD fMRI & $\begin{array}{l}\text { Classical AVM, } \\
\text { healthy controls }\end{array}$ & Severely impaired perilesional cerebrovascular reserve \\
\hline Saliou et al., 2011 & 12 & MR perfusion & $\begin{array}{l}\text { Classical AVM, } \\
\text { AVM w/ angio- } \\
\text { genic features }\end{array}$ & CPA associated w/ increased CBV, MTT, \& increased microvascular leakage \\
\hline Vargas \& Castillo, 2011 & 3 & MR perfusion & None & Increased CBV, CBF, delayed MTT, \& prolonged TTP, suggestive of ischemia \\
\hline Kimiwada et al., 2013 & 1 & $\begin{array}{l}\text { MR perfusion } \\
\text { \& }{ }^{123} \text { IIMP } \\
\text { SPECT }\end{array}$ & None & $\begin{array}{l}\text { Increased CBV, CBF, prolonged MTT. Decreased uptake on SPECT in area } \\
\text { adjacent to lesion. Acetazolamide-stressed SPECT demonstrated further } \\
\text { decreased cerebrovascular reactivity over affected hemisphere }\end{array}$ \\
\hline Kolderman et al., 2014 & 1 & ${ }^{18} \mathrm{~F}-\mathrm{FDG}$ PET & None & Moderate to severe hypometabolism of affected hemisphere \\
\hline Kono \& Terada, 2014 & 1 & $\begin{array}{l}\text { 99mTC-ECD } \\
\text { SPECT }\end{array}$ & None & $\begin{array}{l}\text { Hypoperfusion \& severely impaired cerebrovascular reactivity w/ \& w/o } \\
\text { acetazolamide over affected hemisphere }\end{array}$ \\
\hline Liu et al., 2016 & 5 & PET & None & Hypoperfusion over affected hemisphere in all pts \\
\hline
\end{tabular}

cular reactivity in two studies. ${ }^{13,15}$ A single study using PET as an imaging modality demonstrated hypometabolism over the affected hemisphere. ${ }^{14}$ Two imaging studies utilized comparison groups in an attempt to identify discrete differences between CPA and arteriovenous malformations. Fierstra et al. utilized BOLD sequences in combination with induced changes in end-tidal partial pressure of carbon dioxide to assess cerebrovascular reac-

TABLE 2. Conservatively managed studies

\begin{tabular}{|c|c|c|c|c|c|c|}
\hline Authors \& Year & $\begin{array}{l}\text { Sample } \\
\text { Size }\end{array}$ & Treatment & $\begin{array}{l}\text { Medication } \\
\text { Regimen }\end{array}$ & Clinical Outcome & $\begin{array}{l}\text { Radiological } \\
\text { Outcome }\end{array}$ & $\begin{array}{c}\text { FU } \\
\text { Duration }\end{array}$ \\
\hline Ducreux et al., 2002 & 1 & Conservative & & & & \\
\hline Lasjaunias et al., 2008 & 24 & Conservative & & & & \\
\hline Dória-Netto et al., 2010 & 1 & Conservative & & Persistent symptoms & & $6 \mathrm{mos}$ \\
\hline Maekawa et al., 2012 & 1 & Conservative & & $\begin{array}{l}\text { Progressive neurological deficits } \\
\text { followed by fatal ICH }\end{array}$ & $\begin{array}{l}\text { No progressive } \\
\text { changes }\end{array}$ & 9 yrs \\
\hline Gold \& Crawford, 2013 & 1 & Conservative & & Persistent symptoms & $\begin{array}{l}\text { No progressive } \\
\text { changes }\end{array}$ & $1 \mathrm{yr}$ \\
\hline Khan et al., 2013 & 1 & Conservative & & & & \\
\hline Kimiwada et al., 2013 & 1 & Conservative & AEDs & $\begin{array}{l}\text { Improved symptoms \& neurological } \\
\text { deficits }\end{array}$ & & $1 \mathrm{yr}$ \\
\hline Srivastava et al., 2013 & 1 & Conservative & AEDs & Improved symptoms & & $1 \mathrm{mo}$ \\
\hline Kumar et al., $2015^{16}$ & 1 & Conservative & & Improved symptoms & & $1 \mathrm{yr}$ \\
\hline Kumar et al., $2015^{17}$ & 1 & Conservative & Acetazolamide & Improved symptoms & & $6 \mathrm{mos}$ \\
\hline Bilaj et al., 2016 & 1 & Hematoma evacuation & & & & \\
\hline Liu et al., 2016 & 4 & Conservative & & $\begin{array}{l}\text { Persistent symptoms ( } n=1) \text {, progres- } \\
\text { sive neurological deficits }(n=2)\end{array}$ & $\begin{array}{l}\text { Imaging progres- } \\
\text { sion }(n=1)\end{array}$ & $3-6$ yrs \\
\hline Karian et al., 2017 & 1 & Conservative & Aspirin & & & \\
\hline Gatto et al., 2018 & 1 & Non-targeted embolization & & & & \\
\hline Maekawa et al., 2018 & 1 & Conservative & AEDs & $\begin{array}{l}\text { Multiple ICHs followed by fatal } \\
\text { outcome (unrelated cause) }\end{array}$ & $\begin{array}{l}\text { Imaging progres- } \\
\quad \operatorname{sion}(n=1)\end{array}$ & $30 \mathrm{yrs}$ \\
\hline
\end{tabular}

AEDs = antiepileptic drugs; FU = follow-up; ICH = intracranial hemorrhage. 
TABLE 3. Radiation treatment studies

\begin{tabular}{cccccc}
\hline Authors \& Year & Sample Size & Treatment & Clinical Outcome & Radiological Outcome & FU Duration \\
\hline Hong et al., 2010 & 1 & $\begin{array}{c}\text { Focused Gamma Knife } \\
\text { radiosurgery }\end{array}$ & $\begin{array}{c}\text { Improved headache, persistent } \\
\text { neurological deficit }\end{array}$ & Imaging progression & 8 yrs \\
\hline
\end{tabular}

tivity among patients with CPA compared to patients with AVMs and normal healthy controls. They demonstrated statistically significant impairments in cerebrovascular reactivity among patients with CPA over the affected hemisphere, which increased incrementally in proximity to the malformation. ${ }^{6}$ Saliou et al. compared MR perfusion parameters between patients with CPA and patients with an AVM with and without angiogenic features. Discrete differences in perfusion parameters were detected and were thought to be related to the angiogenic differences between the groups. ${ }^{27}$

\section{Conservative Management}

Of the 9 studies reporting conservative management, 5 reported unfavorable clinical outcomes after presentation, including persistent symptoms, progression of neurological deficits, and intracranial hemorrhage..$^{2,9,19-21}$ The remaining 4 studies reported favorable clinical outcomes, including 2 patients treated with antiepileptic drugs and 1 patient receiving acetazolamide. ${ }^{13,16,17,28}$ Two of 4 studies describing radiological outcomes following conservative management reported adverse radiological progression, including increased size of the malformation and progressive angiogenesis. ${ }^{19,21}$ The remaining studies reported no progressive changes $;{ }^{9}$ however, 1 patient suffered a fatal intracranial hemorrhage after a 9-year period of radiographic quiescence. ${ }^{20}$

\section{Revascularization}

Six studies including 7 patients described revascularization as a treatment modality for CPA. All studies utilized indirect forms of revascularization with 3 patients receiving calvarial burr holes, ${ }^{18,26}$ and the remaining 4 receiving various forms of encephaloduroarteriosynangiosis (EDAS). ${ }^{4,15,19,25}$ No studies utilized direct revascularization.

Two studies described strategies for localizing the re- gion for revascularization. Kono and Terada targeted the precentral region for superficial temporal artery (STA) pial synangiosis on the basis of deteriorating motor function as well as worsening angiographic characteristics of CPA in that region. ${ }^{15}$ Ellis et al. hypothesized that the right hemisphere was hemodynamically compromised and attempted to augment flow to the entire hemisphere by STA pial synangiosis. ${ }^{4}$

Five studies reported improved clinical outcomes, including improvement in headaches and neurological deficits. ${ }^{4,15,18,19,26}$ In the study by Lasjaunias et al., improvement in headache following creation of calvarial burr holes was described as "dramatic and persisting." 18 Liu et al. also noted cessation of headaches as well as resolution of transient motor weakness in their patient treated with EDAS.19 Cessation of worsening motor deficits was noted in two further studies. Kono and Terada noted a deterioration in grip strength from $60 \mathrm{~kg}$ to $0 \mathrm{~kg}$ over the course of 1 year in a patient with CPA..$^{15}$ EDAS halted further motor deterioration and provided a mild increase in grip strength to $5 \mathrm{~kg}$. Ellis et al. also noted improved motor function following EDAS. ${ }^{4}$ Finally, cessation of adverse cerebrovascular events was noted in two studies. Ellis et al. noted no further transient ischemic events occurring following EDAS. ${ }^{4}$ Sakata et al. made 3 burr holes that resulted in no further adverse cerebrovascular events after an early hemorrhage.$^{26}$ One study noted a neurological deficit developing 2 years after cerebral revascularization..$^{25}$

Radiological outcomes reported in 3 studies demonstrated diffuse neovascularization following cerebral revascularization. ${ }^{4,26,15}$ Ellis et al. demonstrated robust revascularization of the perinidal region 8 months following EDAS. ${ }^{4}$ Likewise, Sakata et al. also demonstrated neovascularization occurring 24 months after the placement of calvarial burr holes. ${ }^{26}$ Kono and Terada showed profound revascularization on catheter-based angiography 7 months following EDAS, including regression of the malformation in the region of revascularization. ${ }^{15}$ They were also

TABLE 4. Endovascular embolization studies

\begin{tabular}{|c|c|c|c|c|c|}
\hline Authors \& Year & $\begin{array}{l}\text { Sample } \\
\text { Size }\end{array}$ & Treatment & Clinical Outcome & $\begin{array}{l}\text { Radiological } \\
\text { Outcome }\end{array}$ & $\begin{array}{c}\text { FU } \\
\text { Duration }\end{array}$ \\
\hline $\begin{array}{l}\text { Lasjaunias et al., } \\
\quad 2008\end{array}$ & 23 & Targeted embolization & & & \\
\hline $\begin{array}{l}\text { Marks \& Steinberg, } \\
2012\end{array}$ & 1 & $\begin{array}{l}\text { Targeted embolization of ECA; pial } \\
\text { supply of shunt; VEGF inhibitor }\end{array}$ & $\begin{array}{l}\text { Progression of neurological deficits w/ fatal } \\
\text { outcome (unclear if death related to CPA) }\end{array}$ & $\begin{array}{l}\text { Imaging progres- } \\
\text { sion }\end{array}$ & $6 \mathrm{yrs}$ \\
\hline Sakata et al., 2016 & 1 & $\begin{array}{l}\text { Targeted embolization of } A_{1} \text { pseudo- } \\
\text { aneurysm; calvarial burr holes }\end{array}$ & $\begin{array}{l}\text { No focal neurological deficits \& no further cere- } \\
\text { brovascular events after early rehemorrhage }\end{array}$ & $\begin{array}{l}\text { Obliteration of } \\
\text { pseudoaneurysm }\end{array}$ & $2 \mathrm{yrs}$ \\
\hline $\begin{array}{l}\text { Giragani et al., } \\
2018\end{array}$ & 1 & $\begin{array}{l}\text { Targeted embolization of AICA flow- } \\
\text { related aneurysm using Onyx }\end{array}$ & No new neurological deficits & $\begin{array}{l}\text { Obliteration of } \\
\text { aneurysm }\end{array}$ & $6 \mathrm{mos}$ \\
\hline
\end{tabular}

$\mathrm{AICA}=$ anterior inferior cerebellar artery; $\mathrm{ECA}=$ external carotid artery; VEGF = vascular endothelial growth factor . 
TABLE 5. Revascularization studies

\begin{tabular}{|c|c|c|c|c|c|}
\hline $\begin{array}{l}\text { Authors \& } \\
\text { Year }\end{array}$ & $\begin{array}{l}\text { Sample } \\
\text { Size }\end{array}$ & Treatment & Clinical Outcome & Radiological Outcome & $\begin{array}{c}\text { FU } \\
\text { Duration }\end{array}$ \\
\hline $\begin{array}{l}\text { Lasjaunias et } \\
\text { al., } 2008\end{array}$ & 2 & Calvarial burr holes & Improved headache & & $2-5 \mathrm{yrs}$ \\
\hline $\begin{array}{l}\text { Ellis et al., } \\
\qquad 2011\end{array}$ & 1 & $\begin{array}{l}\text { Pial synangiosis, EMS, dural } \\
\text { inversion }\end{array}$ & $\begin{array}{l}\text { Improved motor deficit \& } \\
\text { cessation of transient } \\
\text { ischemic events }\end{array}$ & Diffuse neovascularization & $12 \mathrm{mos}$ \\
\hline $\begin{array}{l}\text { Kono \& } \\
\text { Terada, } \\
2014\end{array}$ & 1 & STA EDAS & Improved motor deficit & $\begin{array}{l}\text { Neovascularization w/ regression of malformation } \\
\text { in the corresponding region. Slight improvement } \\
\text { of hypoperfusion demonstrated by SPECT }\end{array}$ & 9 mos \\
\hline $\begin{array}{l}\text { Liu et al., } \\
2016\end{array}$ & 1 & EDAS & $\begin{array}{l}\text { Improved headache \& } \\
\text { resolution of transient } \\
\text { neurological deficits }\end{array}$ & & $3-6$ yrs \\
\hline $\begin{array}{l}\text { Sakata et al., } \\
2016\end{array}$ & 1 & $\begin{array}{l}\text { Calvarial burr holes, targeted } \\
\text { embolization }\end{array}$ & $\begin{array}{l}\text { Cessation of adverse cere- } \\
\text { brovascular events after } \\
\text { early rehemorrhage }\end{array}$ & Diffuse neovascularization & $2 \mathrm{yrs}$ \\
\hline $\begin{array}{l}\text { Puerta et al., } \\
2017\end{array}$ & 1 & Pial synangiosis \& EMS & Delayed neurological deficit & & \\
\hline
\end{tabular}

EMS = encephalomyosynangiosis.

able to demonstrate baseline impairment of cerebrovascular reactivity utilizing acetazolamide-stressed SPECT imaging, which subsequently improved following revascularization..$^{15}$

\section{Discussion}

This systematic review summarizes and evaluates the advanced imaging studies and treatment strategies for CPA, including cerebral revascularization. The overall quality of evidence was low, with no clinical series exceeding the case series level of evidence.

The pathogenesis of CPA is not established. The ischemic hypothesis in CPA is that the diffuse angiogenesis reflects a response to cerebral ischemia from the arteriovenous shunting lesion. ${ }^{18,26}$ This provides the framework supporting revascularization as a treatment for this rare disease. Advanced imaging modalities support this hypothesis. ${ }^{3,6,13-15,18,19,27,29}$ All included studies concluded that cerebral hemodynamic dysregulation could be identified locally and distant from the malformation. The principle that this dysregulation and hypoperfusion is distinct from that found in classical AVMs was supported by two studies utilizing comparison groups. Impairments in perilesional cerebrovascular reserve and increased indices of angiogenesis were found in $\mathrm{CPA}^{6,27}$ compared to normal controls and classical AVMs.

The natural history of CPA is also poorly established, with few conservative studies reporting long-term outcomes. We found reports of aggressive clinical courses ${ }^{19,21}$ with rapidly fatal outcomes ${ }^{20}$ and also of indolent phenotypes with no evidence of progression after medical treatment of seizures. ${ }^{13,17}$ Due to the variable results and poor follow-up, there is little substantive evidence from which to draw meaningful conclusions.

Our review of revascularization techniques for CPA is notable for the absence of any attempts at direct revascu- larization. The presence of proximal artery stenosis lends some physiological rationale to the possibility of direct revascularization. Indirect revascularization allows for gradual angiogenesis that is governed by physiological need and is generally considered a low-risk procedure. ${ }^{4}$ Indirect revascularization may also reduce the risk of ambivalent flow and worsening arteriovenous transit through the shunting lesion.

Discussion in the existing literature describing selection of the target region for revascularization has been limited. Nevertheless, current attempts have all demonstrated neovascularization with largely positive outcomes including a remarkable example of regression of the malformation in the region of revascularization..$^{15}$ Given the typically multilobar distribution of CPA, two indirect revascularization paradigms may be proposed.

First, a regional target for revascularization, as suggested by Kono and Terada, is proposed based on advanced imaging modalities such as MR perfusion or SPECT or on clinical findings. ${ }^{15}$ This may identify local regions of hypoperfusion to target for revascularization with techniques such as EDAS or calvarial burr holes. Careful preoperative angiographic evaluation to identify all collateral sources should be undertaken. As a principle, interruption of existing transdural supply to the lesion should be avoided, and therefore calvarial burr holes may be the preferred form of treatment where transdural supply already exists. An EDAS procedure involving STA pial synangiosis, dural inversion, and/or myosynangiosis will likely be preferred for revascularization of the frontal and temporal convexity, where no transdural supply already exists. If the paramedian frontal, parietal, occipital, or infratentorial region is targeted for revascularization, then burr holes or occipital artery synangiosis may also be required. In an alternate paradigm, the entire affected hemisphere may be considered a target for treatment, as suggested by Ellis et al. ${ }^{4} \mathrm{~A}$ combination of EDAS and/or multiple calvarial burr holes, 
as described in the moyamoya literature, can be considered. ${ }^{5,24}$ Revascularization techniques present a potential treatment approach to CPA by targeting the perilesional hypoxia that perpetuates angiogenesis. Initial results with revascularization indicate favorable clinical outcomes. Demonstration of diffuse cortical neovascularization following revascularization surgery lends some empirical support to the ischemic hypothesis..$^{4,15,19,26}$ Whether this is efficacious in the long-term treatment of pertinent clinical outcomes, such as prevention of intracranial hemorrhage or focal neurological deficits, is uncertain.

Given the inherent difficulties in studying rare diseases, a pragmatic strategy to make progress in understanding and treating CPA is a multiinstitutional consortium contributing sound observational data. Long-term radiological and clinical follow-up may help to establish the likelihood of treatment success outside of trials.

\section{Conclusions}

A small body of radiological and clinical studies support the hypothesis that CPA is a response to perinidal oligemia. Limited studies reporting revascularization as a treatment approach have promising initial results; however, the effect of this intervention on altering natural history remains unclear.

\section{References}

1. Bilaj F, Rroji A, Enesi E, Ruka M, Petrela M: Cerebral proliferative angiopathy with tumor-like hemorrhage: a case report and literature review. Neuroradiol J 29:336-339, 2016

2. Dória-Netto HL, Souza-Filho AM, Dória-Netto RH, Marques RA, Oliveira DA, Chaddad-Neto F, et al: Cerebral proliferative angiopathy. Arq Neuropsiquiatr 68:300-302, 2010

3. Ducreux D, Petit-Lacour MC, Marsot-Dupuch K, Bittoun J, Lasjaunias P: MR perfusion imaging in a case of cerebral proliferative angiopathy. Eur Radiol 12:2717-2722, 2002

4. Ellis MJ, Armstrong D, Dirks PB: Large vascular malformation in a child presenting with vascular steal phenomenon managed with pial synangiosis. J Neurosurg Pediatr 7:15-21, 2011

5. Endo M, Kawano N, Miyaska Y, Yada K: Cranial burr hole for revascularization in moyamoya disease. J Neurosurg 71:180-185, 1989

6. Fierstra J, Spieth S, Tran L, Conklin J, Tymianski M, ter Brugge KG, et al: Severely impaired cerebrovascular reserve in patients with cerebral proliferative angiopathy. $\mathbf{J}$ Neurosurg Pediatr 8:310-315, 2011

7. Gatto LAM, Brisson RT, Demartini Z, Koppe G, Rocha C Jr: Cerebral proliferative angiopathy: case report. Arq Bras Neurocir 37:131-133, 2018

8. Giragani S, Pavunesan SK, Balasubramaniam A: Targeted endovascular treatment of haemorrhagic posterior fossa proliferative angiopathy. Interv Neuroradiol 24:440-443, 2018

9. Gold JJ, Crawford JR: Acute hemiparesis in a child as a presenting symptom of hemispheric cerebral proliferative angiopathy. Case Rep Neurol Med 2013:920859, 2013

10. Hong KS, Lee JI, Hong SC: Neurological picture. Cerebral proliferative angiopathy associated with haemangioma of the face and tongue. J Neurol Neurosurg Psychiatry 81:36-37, 2010

11. Karian V, Rabner J, LeBel A: Cerebral proliferative angiopathy. Pediatr Neurol 66:115-116, 2017
12. Khan A, Rattihalli R, Beri S, Dickinson F, Hussain N, Gosalakkal J: Cerebral proliferative angiopathy: a rare form of vascular malformation. J Paediatr Child Health 49:504505,2013

13. Kimiwada T, Hayashi T, Shirane R, Tominaga T: ${ }^{123} \mathrm{I}-\mathrm{IMP}-$ SPECT in a patient with cerebral proliferative angiopathy: a case report. J Stroke Cerebrovasc Dis 22:1432-1435, 2013

14. Kolderman SEM, Noordzij W, van Dijk JMC, Luijckx GJR: Nuclear imaging in proliferative angiopathy. Eur J Nucl Med Mol Imaging 41:810, 2014

15. Kono K, Terada T: Encephaloduroarteriosynangiosis for cerebral proliferative angiopathy with cerebral ischemia. J Neurosurg 121:1411-1415, 2014

16. Kumar S, Sharma M, Srivastava T, Sinha VD: Infratentorial hemorrhagic cerebral proliferative angiopathy: a rare presentation of a rare disease. Asian J Neurosurg 10:240242, 2015

17. Kumar S, Srivastava T, Tejwani S, Khilnani K: Cerebral proliferative angiopathy with papilledema. Clin Neurol Neurosurg 139:12-15, 2015

18. Lasjaunias PL, Landrieu P, Rodesch G, Alvarez H, Ozanne A, Holmin S, et al: Cerebral proliferative angiopathy: clinical and angiographic description of an entity different from cerebral AVMs. Stroke 39:878-885, 2008

19. Liu P, Lv X, Lv M, Li Y: Cerebral proliferative angiopathy: clinical, angiographic features and literature review. Interv Neuroradiol 22:101-107, 2016

20. Maekawa H, Tanaka M, Hadeishi H: Fatal hemorrhage in cerebral proliferative angiopathy. Interv Neuroradiol 18:309-313, 2012

21. Maekawa H, Terada A, Ishiguro T, Komiyama M, Lenck $\mathrm{S}$, Renieri L, et al: Recurrent periventricular hemorrhage in cerebral proliferative angiopathy: case report. Interv Neuroradiol 24:713-717, 2018

22. Marks MP, Steinberg GK: Cerebral proliferative angiopathy. J Neurointerv Surg 4:e25, 2012

23. Moher D, Liberati A, Tetzlaff J, Altman DG: Preferred reporting items for systematic reviews and meta-analyses: the PRISMA statement. PLoS Med 6:e1000097, 2009

24. Patel NN, Mangano FT, Klimo P Jr: Indirect revascularization techniques for treating moyamoya disease. Neurosurg Clin N Am 21:553-563, 2010

25. Puerta P, Guillén A, Muchart J, González V, Ferrer E: Cerebral proliferative angiopathy in a child. Pediatr Neurosurg 52:214-216, 2017

26. Sakata H, Fujimura M, Sato K, Niizuma K, Endo H, Tominaga T: Development of abnormal hemispheric vascular networks mimicking cerebral proliferative angiopathy in a child originally diagnosed with deep-seated arteriovenous fistula. J Stroke Cerebrovasc Dis 25:e200-e204, 2016

27. Saliou G, Krings T, Rutgers DR, Toulgoat F, Ozanne A, Lasjaunias P, et al: PWI-MRI and contrast extravasation in brain AVM help to estimate angiogenic activity. Neuroradiology 53:793-800, 2011

28. Srivastava T, Mathur T, Jain R, Sannegowda RB: Cerebral proliferative angiopathy: a rare clinical entity with peculiar angiographic features. Ann Indian Acad Neurol 16:674675,2013

29. Vargas MC, Castillo M: Magnetic resonance perfusion imaging in proliferative cerebral angiopathy. J Comput Assist Tomogr 35:33-38, 2011

\section{Disclosures}

The authors report no conflict of interest concerning the materials or methods used in this study or the findings specified in this paper. 


\section{Author Contributions}

Conception and design: all authors. Acquisition of data: Somji. Analysis and interpretation of data: Somji. Drafting the article: all authors. Critically revising the article: all authors. Reviewed submitted version of manuscript: all authors. Approved the final version of the manuscript on behalf of all authors: Somji. Administrative/technical/material support: Somji.

\section{Correspondence}

Mohamed Somji: Health Sciences Centre, University of Manitoba,

Winnipeg, MB, Canada. somjim3@myumanitoba.ca. 